\title{
Joint interpretation of magnetotelluric, seismic, and well-log data in Hontomín (Spain)
}

\author{
Xènia Ogaya ${ }^{1}$, Juan Alcalde ${ }^{2}$, Ignacio Marzán ${ }^{3}$, Juanjo Ledo ${ }^{4}$, Pilar Queralt ${ }^{4}$, Alex Marcuello ${ }^{4}$, David Martí ${ }^{3}$, \\ Eduard Saura $^{3}$, Ramon Carbonell ${ }^{3}$, and Beatriz Benjumea ${ }^{5}$ \\ ${ }^{1}$ Dublin Institute for Advanced Studies, School of Cosmic Physics, Dublin 2, Ireland \\ ${ }^{2}$ Department of Geology and Petroleum Geology, University of Aberdeen, Aberdeen, UK \\ ${ }^{3}$ Institute of Earth Sciences Jaume Almera ICTJA-CSIC, Barcelona, Spain \\ ${ }^{4}$ GEOMODELS Research Institute, Dept. Dinàmica de la Terra i de l'Oceà, Facultat de Geologia, \\ Universitat de Barcelona, Barcelona, Spain \\ ${ }^{5}$ Institut Cartogràfic i Geològic de Catalunya ICGC, Parc de Montjuïc, 08038 Barcelona, Spain \\ Correspondence to: Xènia Ogaya (xogaya@cp.dias.ie)
}

Received: 31 January 2016 - Published in Solid Earth Discuss.: 4 February 2016

Revised: 10 May 2016 - Accepted: 17 May 2016 - Published: 9 June 2016

\begin{abstract}
Hontomín (N of Spain) hosts the first Spanish $\mathrm{CO}_{2}$ storage pilot plant. The subsurface characterization of the site included the acquisition of a 3-D seismic reflection and a circumscribed 3-D magnetotelluric (MT) survey. This paper addresses the combination of the seismic and MT results, together with the available well-log data, in order to achieve a better characterization of the Hontomín subsurface. We compare the structural model obtained from the interpretation of the seismic data with the geoelectrical model resulting from the MT data. The models correlate well in the surroundings of the $\mathrm{CO}_{2}$ injection area with the major structural differences observed related to the presence of faults. The combination of the two methods allowed a more detailed characterization of the faults, defining their geometry, and fluid flow characteristics, which are key for the risk assessment of the storage site. Moreover, we use the well-log data of the existing wells to derive resistivity-velocity relationships for the subsurface and compute a 3-D velocity model of the site using the 3-D resistivity model as a reference. The derived velocity model is compared to both the predicted and logged velocity in the injection and monitoring wells, for an overall assessment of the computed resistivityvelocity relationships. The major differences observed are explained by the different resolution of the compared geophysical methods. Finally, the derived velocity model for the near surface is compared with the velocity model used for the static corrections in the seismic data. The results allowed
\end{abstract}

extracting information about the characteristics of the shallow unconsolidated sediments, suggesting possible clay and water content variations. The good correlation of the velocity models derived from the resistivity-velocity relationships and the well-log data demonstrate the potential of the combination of the two methods for characterizing the subsurface, in terms of its physical properties (velocity, resistivity) and structural/reservoir characteristics. This work explores the compatibility of the seismic and magnetotelluric methods across scales highlighting the importance of joint interpretation in near surface and reservoir characterization.

\section{Introduction}

Geophysical characterization is the main tool to unravel the complex physical properties of the subsurface and is the central part of the characterization of geological reservoirs. The characterization of reservoirs dedicated to $\mathrm{CO}_{2}$ geological storage requires an extensive preliminary geophysical study according to best practice manuals and reports (e.g. IPCC, 2005; Chadwick et al., 2008), and governmental directives (e.g. EU Directive, 2009). Reflection seismics is a powerful geophysical tool for subsurface imaging and it is largely used to characterize the subsurface for resource exploration (e.g. Hart, 1999; Hesthammer et al., 2001). The interpretation of the seismic images provides important constrains on the ge- 


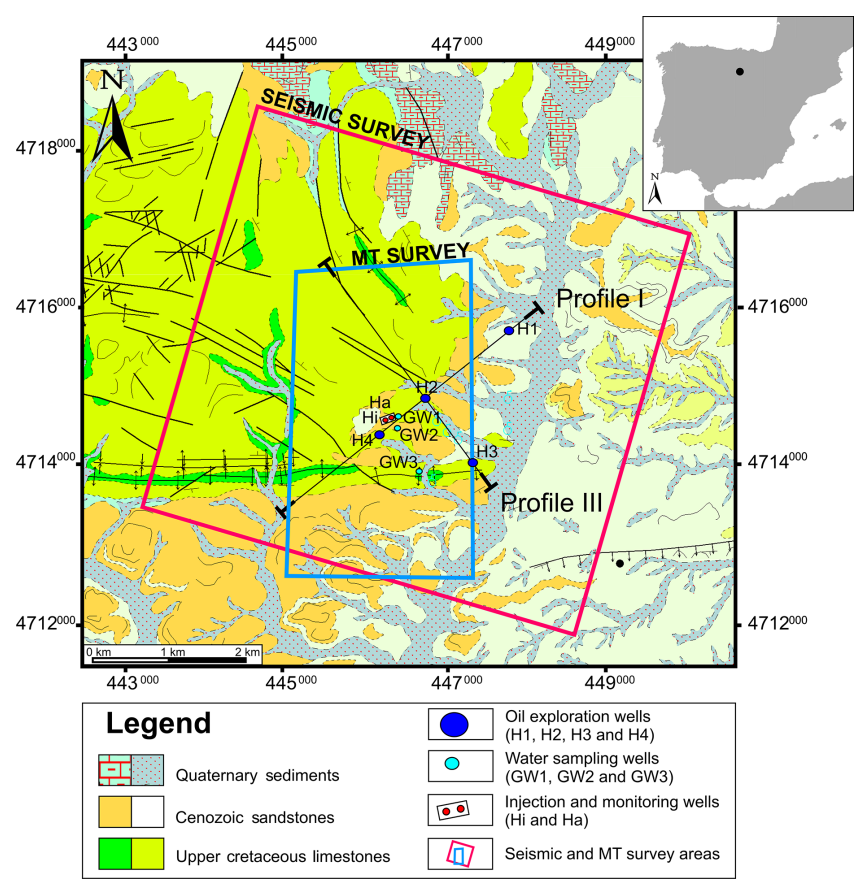

Figure 1. Location of the study area, MT survey, seismic survey, and wells. Profiles I and III refer to the position of the cross-sections shown in Fig. 5.

ological structures, and the analysis of the data allows inferring information on the subsurface velocity field. However, seismic data is unable to provide information on pore fluid nature and is not very sensitive to fluid saturation (e.g. Eid et al., 2015). On the other hand, electromagnetics, for example the magnetotelluric method (MT), are particularly suitable for fluid characterization purposes, thanks to their sensitivity to changes in the electrical conductivity of the pore space directly linked to changes in fluid saturation (Bedrosian, 2007; Nakatsuka et al., 2010; MacGregor, 2012). Joint inversion of magnetotelluric and seismic data is a promising practice to resolve different aspects of the same structure (e.g. Gallardo and Meju, 2003), but its application is computationally expensive and the algorithms used are still under development (Moorkamp et al., 2011). Joint interpretation of seismic and electromagnetic data have proven successful in subsurface characterization (e.g. Harris and MacGregor, 2006; Juanatey et al., 2013; Solon et al., 2015). Hence, a compelling reservoir characterization will benefit from the integration of the structural interpretation, provided by the seismic image, with the electrical properties derived from the MT method (e.g. Eberhart-Phillips et al., 1995; Muñoz et al., 2010).

Hontomín, a Jurassic domed anticline structure located in the SW portion of the Basque-Cantabrian basin ( $\mathrm{N}$ of Spain, Fig. 1), hosts the first pilot site in Spain for $\mathrm{CO}_{2}$ geological storage in a deep saline aquifer. Successful $\mathrm{CO}_{2}$ storage sites include a complete characterization, dedicated to understanding the characteristics of the subsurface as well as ensuring the suitability, safety, and security of the site (e.g. Chadwick et al., 2004; Förster et al., 2006; White, 2013). The selection of Hontomín as a pilot $\mathrm{CO}_{2}$ storage site motivated a multidisciplinary characterization of the area, aimed to unravel the main characteristics of the subsurface structures. This includes geochemical (Elío et al., 2013; Nisi et al., 2013; Permanyer et al., 2013), geophysical (Rubio et al., 2011; Alcalde et al., 2013a, b, 2014; Ogaya et al., 2013, 2014; Ugalde et al., 2013; Vilamajó et al., 2013, 2015; Benjumea et al., 2016) and hydro/geomechanical (Canal et al., 2013; Martínez-Landa et al., 2013) studies. Amongst them, this work aims to integrate the seismic (Alcalde et al., 2013a, b; 2014) and MT (Ogaya et al., 2013, 2014) characterization results, together with the available log data, to expand our knowledge of the subsurface of Hontomín.

In this paper, we carry out a joint interpretation of the structural model from seismics and the geoelectrical model from magnetotellurics. The logged data of the existing wells are used to derive empirical resistivity-velocity relationships for the subsurface and to compute velocity models using the geoelectrical model as a reference. The static corrections model of the site is presented for the first time in this work and its correlation with the derived velocity models is used to better characterize the shallow subsurface. The recently available data of the injection and monitoring wells of the Hontomín site are also used to validate the results.

\section{Geophysical setting}

\subsection{Well-log data}

The study area has been explored for hydrocarbon resources and contains four hydrocarbon exploration wells (depths up to $1769 \mathrm{~m}$ true vertical depth - TVD) drilled between the late 1960s and 2007 (H1, H2, H3, and H4, Fig. 1). However, their overall production never exceeded $3000 \mathrm{bbl}$ (Permanyer et al., 2013). In 2012 three shallow hydrogeological wells (depths between 150 and $405 \mathrm{~m}$ TVD) were drilled in the framework of the $\mathrm{CO}_{2}$ storage project to carry out groundwater studies (GW1, GW2, and GW3 - Benjumea et al., 2016, Fig. 1). Finally, in 2013, the injection (Hi) and the monitoring (Ha) wells (Fig. 1) were drilled as a part of the $\mathrm{CO}_{2}$ storage plant (depths up to $1580 \mathrm{~m}$ TVD). The resistivity logged data of the $\mathrm{H} 4, \mathrm{Hi}$, and $\mathrm{Ha}$ wells are presented for the first time in this work.

\subsection{Seismic dataset}

The seismic characterization in Hontomín included the acquisition of a $36 \mathrm{~km}^{2} 3-\mathrm{D}$ seismic reflection dataset (Alcalde et al., 2013a). The area studied (Fig. 1) ensured the coverage of all the boreholes as well as the entire target dome structure. The quality of the seismic data was hampered by the geological complexity of the study area, summarized in two main geological aspects: (1) the existence of a veloc- 


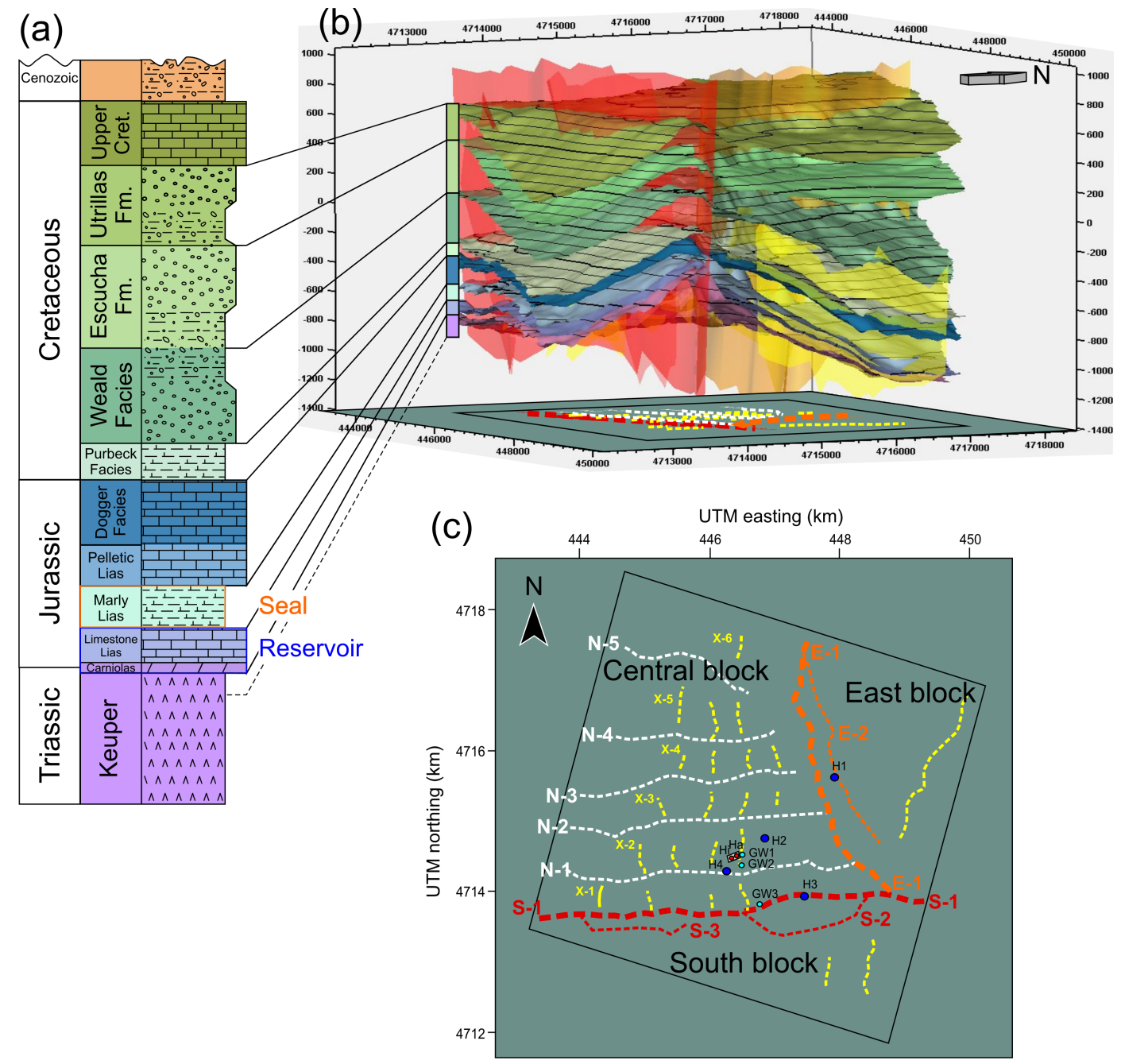

Figure 2. Description of the lithologies and structures interpreted in the subsurface of Hontomín (after Alcalde et al., 2014). (a) Stratigraphic column with relative thicknesses of the sedimentary units. (b) Eight-layered structural model interpreted from the seismic and well-log data; the eight surfaces interpreted are: Anhydrite Unit (top Keuper), Limestone Lias (top of the reservoir formation), Marly Lias (top of the primary seal formation), Dogger facies, Purbeck facies, Weald facies, Escucha Fm., and Utrillas Fm. (c) Sketch with the general distribution and labelling of the main faults interpreted in the study area, including: "S-faults" in red, "E-faults" in orange, "N-faults" in white, and "X-faults" in yellow; S-1 corresponds to the South Fault and E-1 corresponds to the East Fault; these two faults determine the remarkable division of the study area in three blocks: the east, the central, and the south block. The position of the oil exploration and water wells are also included for reference.

ity inversion near the surface produced a loss of first arrival energy in offsets larger than $400 \mathrm{~m}$, creating a so-called "shadow zone" in that portion of the data. This velocity inversion is mostly originated in the transition from high-velocity Upper Cretaceous carbonates to low-velocity Lower Cretaceous siliciclastic sediments, as well as in the shallower marlstone-limestone transition within the Upper Cretaceous layers. (2) The mixed lithologies (siliciclastic and carbonate) present in the entire sedimentary succession produced sharp changes in the propagation velocity that resulted in a blurred seismic signature. These two factors, together with the moderate signal-to-noise ratio $(S / N$ ratio) often present in onshore-acquired data, resulted in a severe lack of co- herency in the deep reflections (Alcalde et al., 2013b). The acquired 3-D seismic dataset was processed up to post-stack time migration (Alcalde et al., 2013b). In spite of the improvement of the resulting image obtained by the processing applied, the limited lateral continuity of the reflections obstructed a direct interpretation of the seismic data. This issue was circumvented by the use of a conceptual model to guide the interpretation (Alcalde et al., 2014). This conceptual model was generated from the available well-log and regional geology data. Further details on the acquisition, processing and interpretation of the 3-D seismic dataset are described in-depth in Alcalde et al. (2013a, b, and 2014, respectively). 

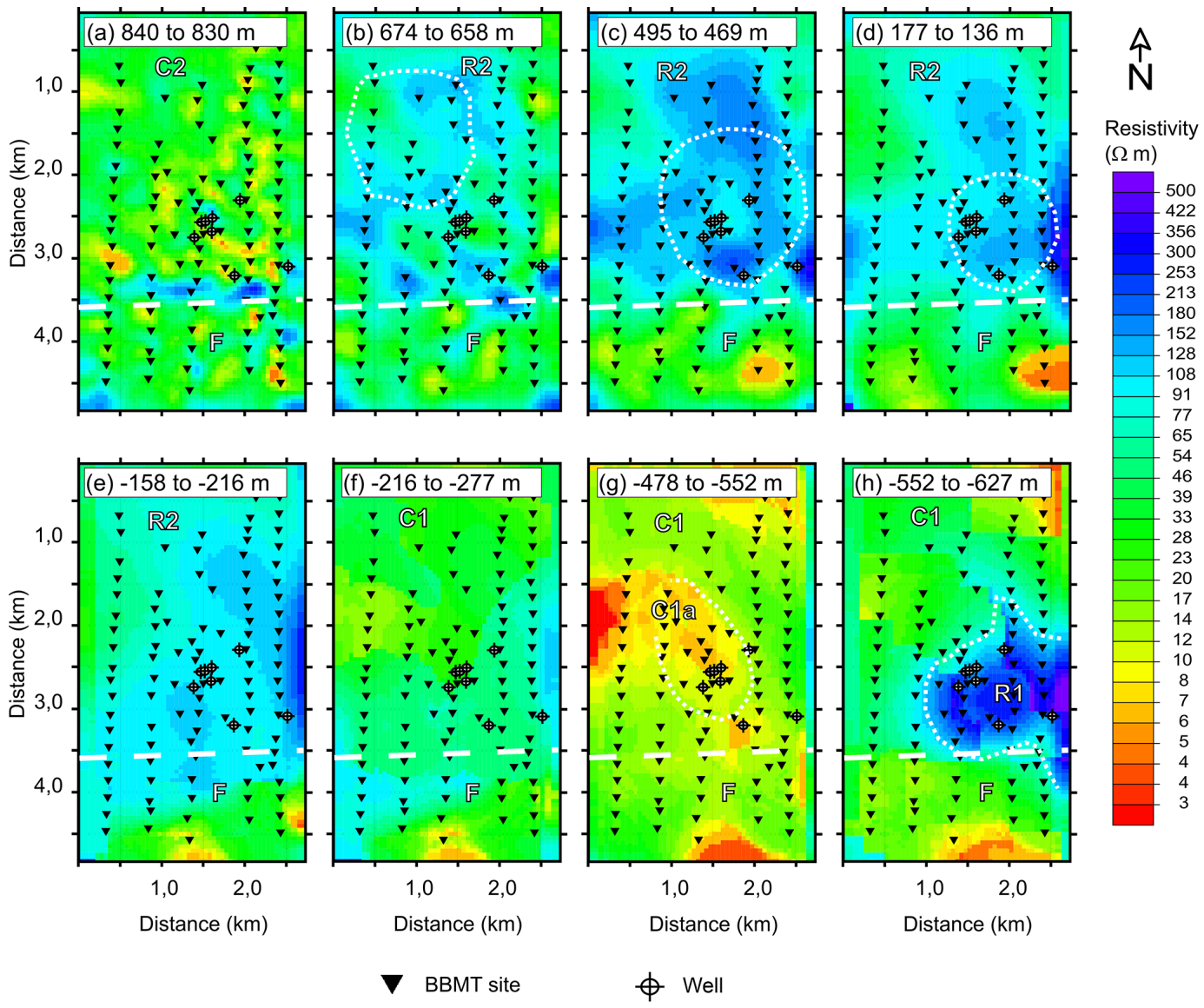

Figure 3. 3-D geoelectrical model (reproduced from Ogaya et al., 2014). Z-slices of the model from top (a) to bottom (h), depths are indicated in each sub-plot. The main resistivity layers (R1, C1, R2, and C2) and the F region are marked. E-W white dashed line indicates the approximate northern border of the F region. From bottom to top (elevation in m a.s.l.): (h) top of the R1 layer; (g) main reservoir C1a (saline aquifer); (f) top of the C1 layer; (e) bottom of the R2 layer; (d), (c) and (b) evolution of the R2 layer's dome structure and (a) C2 layer and bend of the R2 layer due to the presence of the F region (see Ogaya et al., 2014 for more information.).

\subsubsection{Structural model}

The structural model was built from the interpretation of the seismic dataset combined with the available well-logs and regional geological information (Alcalde et al., 2014). The well-log data allowed identification of 39 subunits from 12 major units ranging from the Anhydrite Unit at the bottom to the Cenozoic sediments at the top of the wells. The top surfaces of nine of these 12 major units were interpreted in the seismic volume (Fig. 2a, b). Four sets of faults were also interpreted in the seismic data, the "S-", "E-", "N-", and "Xfaults" (Fig. 2b, c). The interpreted surfaces allowed the successful prediction of the formation tops for the $\mathrm{Hi}$ and $\mathrm{Ha}$ wells (Alcalde et al., 2014).

The nine main surfaces and the four sets of faults allowed understanding the geometries of the subsurface structures in Hontomín (Fig. 2b). The target dome structure is formed by the Jurassic carbonate sediments and cored by Triassic evaporitic sediments (anhydrite and salt). The target reservoir is a saline aquifer hosted in the Limestone Lias unit and lo- cated in the injection area at $1485 \mathrm{~m}$ depth. It is covered by the main seal formation (Marly Lias) composed of marlstones, marly limestones and interbedded black-shales levels. The dome is overlaid by Lower Cretaceous siliciclastic sediments (Weald, Escucha, and Utrillas Fm.) which progressively flatten and lose the dome geometry upwards. The top of the sedimentary sequence is composed by Upper Cretaceous limestones and Cenozoic sediments, outcropping in the study area (Fig. 1). The Upper Cretaceous sediments are karstified, but the extent and geometry of the karstic areas is relatively unknown. Two major faults, S-1 and E-1 (hereafter "South Fault" and "East Fault", respectively) affect the entire stratigraphic sequence (Fig. 2b). They also dominate the structural relief of the Jurassic dome, dividing the area in three blocks (Fig. 2c): central, eastern, and southern blocks. The slip of the faults locate the central block (that includes the target injection area) structurally higher than the eastern and southern blocks. 


\subsection{Magnetotelluric dataset}

The magnetotelluric characterization of the Hontomín site was divided into two stages: a 2-D MT data acquisition carried out in Spring 2010 (Ogaya et al., 2013) and a 3-D MT data acquisition undertaken in Autumn 2010 (Ogaya et al., 2014). In total, a grid of 109 closely spaced broadband magnetotelluric (BBMT) sites was collected covering an areal extent of $15 \mathrm{~km}^{2}$ (Fig. 1). The BBMT sites were deployed along five $\mathrm{N}-\mathrm{S}$ profiles of around $4 \mathrm{~km}$ long and the average distance between them was approximately $500 \mathrm{~m}$. Two smaller profiles were acquired in the injection area to refine the grid in the target region. The stations were distributed at $200 \mathrm{~m}$ intervals along the profiles and the data were acquired in the period range of 0.001 to $100 \mathrm{~s}$. The longer the recorded periods, the deeper is the penetration depth and the lower is the resolution of the magnetotelluric method. The dataset for the 3-D inversion contained the full impedance tensor (MT tensor that relates the orthogonal components of the electric and magnetic field variations recorded on the surface) of 102 BBMT sites in the range of 0.001 to $10 \mathrm{~s}$. Seven BBMT sites and periods longer than $10 \mathrm{~s}$ were discarded for being too noisy. Further details on the acquisition, processing, inversion, and modelling of the MT data are described in-depth in Ogaya et al. (2013 and 2014).

\subsubsection{Geoelectrical model}

The resistivity baseline model of the Hontomín site reveals a geoelectrical structure composed of four main layers (Fig. 3; Ogaya et al., 2014): a resistive bottom layer R1 (below $-600 \mathrm{~m}$ above sea level - ma.s.1.) linked to Keuper facies and to an Anhydrite unit; a conductive layer C1 (below $-200 \mathrm{~m}$ a.s.1. and thickness up to $400 \mathrm{~m}$ ) containing the primary reservoir and seal units; a resistive middle layer R2 (between +700 and $-200 \mathrm{~m}$ a.s.1.) containing the secondary reservoir-seal system, and a conductive top layer $\mathrm{C} 2$ (above +700 m a.s.1.) linked to Upper Cretaceous and Cenozoic materials.

The model shows a smooth dome-like geoelectrical structure with an approximate NW-SE orientation (Fig. 3; Ogaya et al., 2014). The crests of the four interpreted layers follow this direction, from the SE corner (R1) to the NW corner (R2) of the study area. The injection area is located approximately in the crest of the $\mathrm{C} 1$ layer, which has an areal extent of circa $1 \mathrm{~km}^{2}$ (Fig. $3 \mathrm{~g}$ ). The saline aquifer (main reservoir) is linked to the most conductive region inside the $\mathrm{C} 1$ layer (Fig. 3g). The slope of the north flank is less steep and seems to be elongated to the NW. The R2 layer begins at circa $-200 \mathrm{~m}$ a.s.1. and its base is located to the SE of the study area, in the location of the injection and exploration wells (Fig. 3d). Upwards, this layer progressively migrates to the NW, until reaching approximately $+700 \mathrm{~m}$ a.s.l. at its top (Fig. 3b). In the southern part of the model, a conductive zone is observed and interpreted as a fault region ("F region"). The
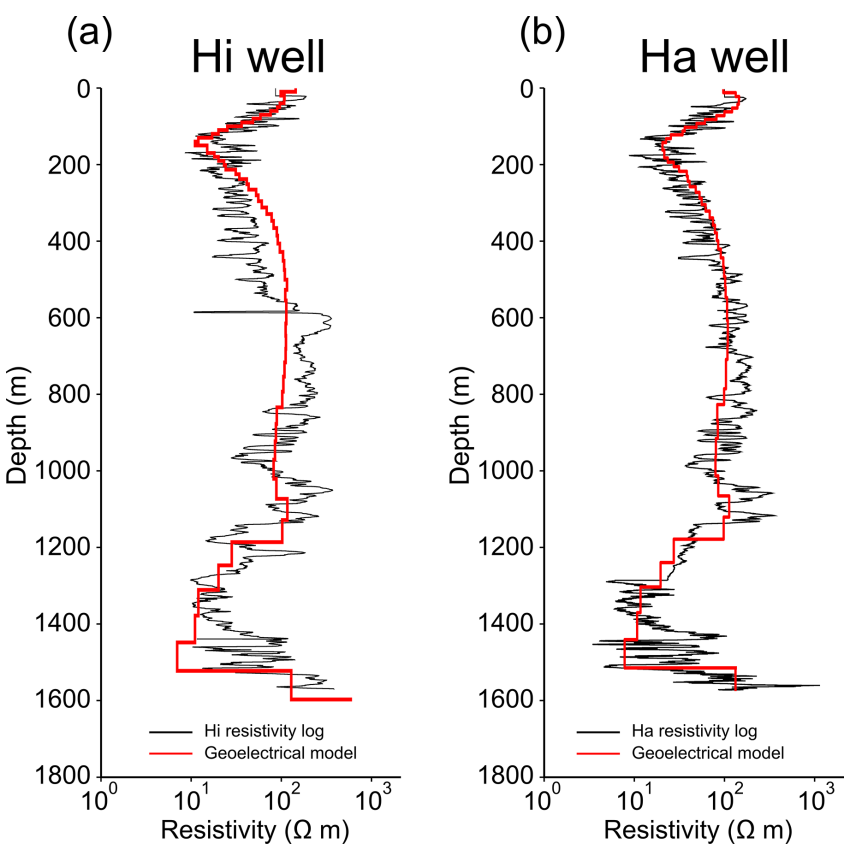

Figure 4. Comparison between the resistivity log data (in black) and resistivity model provided by the column of the 3-D geoelectrical model located at the well position (in red) for the $\mathrm{Hi}$ (a) and $\mathrm{Ha}$ (b) wells.

E-W dashed line in Fig. 3 indicates the approximate northern border of that region. The geoelectrical structure of the F region revealed an important conductive fluid circulation along the fault zone, which was unknown until the MT survey was conducted. Ogaya et al. (2013) concluded that the electrical resistivity variation imaged in the $\mathrm{F}$ region was too high to be produced by the presence of clay in the fault zone. The F region is observed to be more conductive in the eastern part than in the western part, where it seems to split in different fault segments (Fig. 16 in Ogaya et al., 2014). The model suggested that the $F$ region affects all the layers of the model but it does not outcrop at surface (Ogaya et al., 2013, 2014). In general, the R2 layer is more resistive in the eastern part of the model (Fig. 3c, d, e). This more resistive behaviour in the eastern part is certified by the resistivity log data of the H3 well (Fig. 14 in Ogaya et al., 2014). Small resistivity variations are observed inside the R2 layer ("FR2" areas) that could be associated with a set of minor faults in the Dogger and Purbeck units (Ogaya et al., 2014).

The drilling of the Hi and Ha wells was completed at the end of 2013 and their resistivity log data only became available after the publication of the 3-D MT model (Ogaya et al., 2014). The agreement between the geoelectrical structure predicted by the 3-D resistivity model for the $\mathrm{Hi}$ and the Ha wells and their resistivity log data confirms the accuracy and reliability of the geoelectrical model (Fig. 4). The resistivity models displayed in red represent the resistivity values of the column of the 3-D geoelectrical model located at each 
well position. The resistivity models of both wells are very similar to each other because they belong to adjacent lateral cells of the 3-D mesh (the distance between the $\mathrm{Hi}$ and $\mathrm{Ha}$ wells is $50 \mathrm{~m}$ ).

\section{Joint interpretation: seismic structural model - resistivity model}

Two sections of the structural model, profiles $\alpha$ and $\beta$ presented in Alcalde et al. (2014), have been compared to their equivalents in the geoelectrical model, profiles I and III presented in Ogaya et al. (2014; Fig. 5a, b). These two sections cross different wells in the area (see Fig. 1): profile I crosses wells H4, GW2, GW1, H2, and H1, and profile III, wells H2 and $\mathrm{H} 3$.

There is a general agreement between the top of the different units displayed in the structural model interpreted from the seismics, and the top of the bodies imaged in the geoelectrical model in the centre of the study area. The match is not perfect in the flanks of the dome, where the steepness of the flanks imaged by the seismic data is higher than that observed in the MT image. This mismatch is probably partially related to the presence of the South Fault (Fig. 5c). The plane of the South Fault in the structural model coincides with the bend in the vertical plane of the resistive body R 2 and with the position of the $\mathrm{F}$ region interpreted in the geoelectrical model (Fig. 5a). The geoelectrical characteristics suggest that the fracture zone related to the South Fault is a region of ongoing fluid flow. The South Fault is also interpreted in the structural model as a flower structure with multiple splays, and this correlates well with the apparent multiple branching observed in the western part of the conductive $F$ region of the resistivity model (Fig. 16 in Ogaya et al., 2014). In the eastern part of the model (Fig. 5b), the South Fault coincides with the region where the $\mathrm{R} 2$ body is more resistive. The East Fault interpreted in the structural model (plotted in orange in Fig. 5 and called EF in the geoelectrical models) is out of the MT survey region. However, the joint interpretation of the two models seems to indicate that this fault could be the responsible of the more resistive behaviour of the R2 layer on the eastern part of the model. We have associated the resistive characteristics of this area to a potential sealing of the East Fault.

For the joint interpretation of the minor faults, it is worth bearing in mind that faults are imaged as resistivity variations caused by displacement of the layers and/or fluid circulation along fractures in geoelectrical models. If the displacement is below the MT resolution, the faults may still be detected by the seismic method. On the other hand, faults with null displacement might be below the seismic resolution while still being detectable by the MT method if there exists certain fluid circulation. The slight changes observed in the R2 resistivity layer could be associated to the presence of the $\mathrm{N}$ faults (in white in Fig. 5). However, since the resistivity
Table 1. Empirical relationship ER1: linear regression of $V$ vs. $\log (R)$.

\begin{tabular}{lrrrr}
\hline Group & Depth $(\mathrm{m})$ & $a\left(\Omega^{-1} \mathrm{~s}^{-1}\right)$ & $b\left(\mathrm{~m} \mathrm{~s}^{-1}\right)$ & $R^{2}$ \\
\hline S1 & $0-100$ & $2.68 \times 10^{3^{*}}$ & $-1.33 \times 10^{3^{*}}$ & 0.6 \\
S2 & $100-150$ & $1.41 \times 10^{3^{*}}$ & $4.90 \times 10^{2^{*}}$ & 0.1 \\
S3 & $150-200$ & $2.39 \times 10^{3^{*}}$ & $-5.45 \times 10^{2^{*}}$ & 0.3 \\
S4 & $200-300$ & $-4.70 \times 10^{1}$ & $2.39 \times 10^{3^{*}}$ & 0.001 \\
S5 & $300-400$ & $4.68 \times 10^{1}$ & $2.33 \times 10^{3^{*}}$ & 0.002 \\
D1 & $456-573$ & $9.54 \times 10^{1}$ & $2.80 \times 10^{3^{*}}$ & 0.007 \\
D2 & $573-620$ & $7.19 \times 10^{2^{*}}$ & $1.88 \times 10^{3^{*}}$ & 0.3 \\
D3 & $620-750$ & $4.28 \times 10^{2^{*}}$ & $2.28 \times 10^{3^{*}}$ & 0.1 \\
D4 & $750-958$ & $3.15 \times 10^{2^{*}}$ & $2.70 \times 10^{3^{*}}$ & 0.09 \\
D5 & $958-986$ & $1.13 \times 10^{2}$ & $3.14 \times 10^{3^{*}}$ & 0.03 \\
D6 & $986-1076$ & $5.60 \times 10^{1}$ & $3.51 \times 10^{3^{*}}$ & 0.003 \\
D7 & $1076-1150$ & $1.23 \times 10^{3^{*}}$ & $2.56 \times 10^{3^{*}}$ & 0.6 \\
D8 & $1150-1193$ & $1.39 \times 10^{3^{*}}$ & $2.55 \times 10^{3^{*}}$ & 0.92 \\
D9 & $1193-1239$ & $1.79 \times 10^{3^{*}}$ & $2.09 \times 10^{3^{*}}$ & 0.96 \\
D10 & $1239-1411$ & $1.94 \times 10^{3^{*}}$ & $2.10 \times 10^{3^{*}}$ & 0.92 \\
D11 & $1411-1442$ & $-2.30 \times 10^{2}$ & $4.18 \times 10^{3^{*}}$ & 0.02 \\
D12 & $1442-1611$ & $1.13 \times 10^{3^{*}}$ & $3.22 \times 10^{3^{*}}$ & 0.6 \\
\hline
\end{tabular}

$* p$ value $<0.02$.

changes observed in the geoelectrical model are not obvious, we cannot anticipate fluid circulation along these fractures. The X-faults (in yellow in Fig. 5) were not imaged in the geoelectrical model, suggesting that their displacement is below the resolution of the MT method at that depth and that there is no indication of important fluid circulation associated to these faults. The minor faults FR2 detected in the geoelectrical model (Fig. 5) are not observed in the structural model. This could be due to the existence of small scale faults or fractures, with null or very small displacement but sufficient fluid circulation to produce resistivity changes in the R2 layer.

\section{Deriving velocity from resistivity}

\subsection{Resistivity-velocity relationships}

Resistivity-velocity relationships have been used to calculate one physical parameter as a function of the other in numerous works (e.g. Faust, 1953; Brito dos Santos et al., 1988; Hacikoylu et al., 2006; Werthmüller et al., 2013). In Hontomín, the log data of the GW1 and the H4 wells were used to derive resistivity-velocity relationships for the subsurface and compute a 3-D velocity model of the site, using the 3-D resistivity model as a reference. These two wells were chosen because of their suitable location in the surroundings of the injection area (Fig. 1) and the availability of their almost complete resistivity and velocity log data. The GW1 data were used for the shallow subsurface, from 24.35 to $400 \mathrm{~m}$ 
(a)

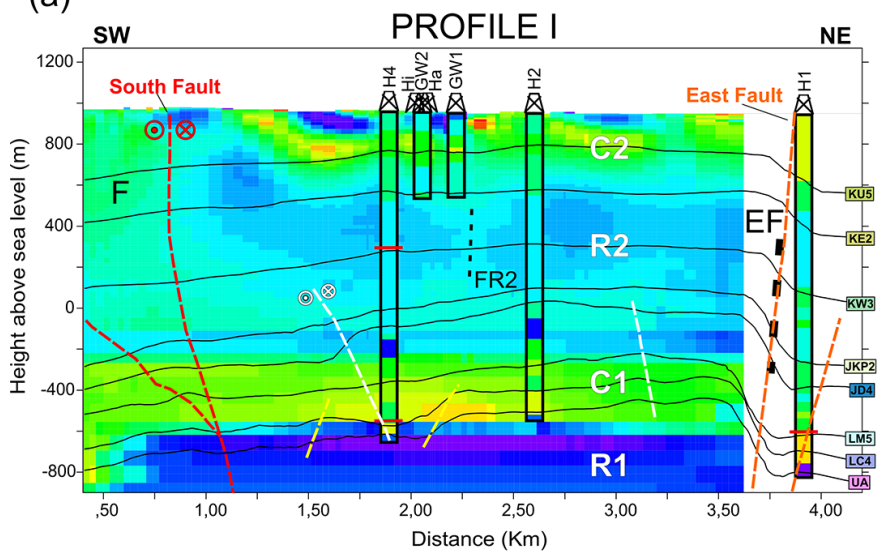

(b)

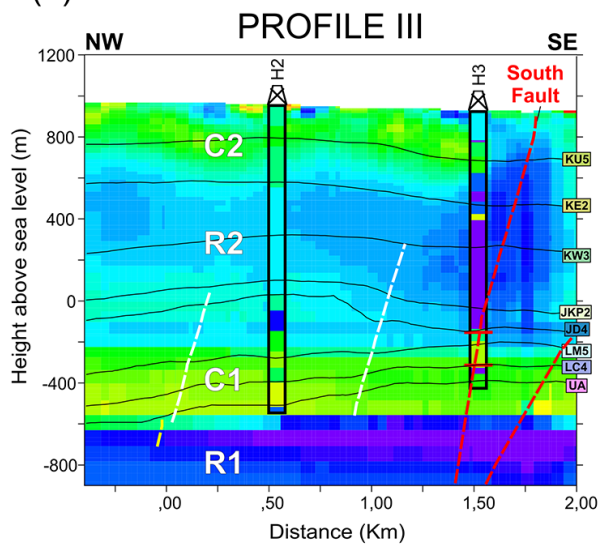

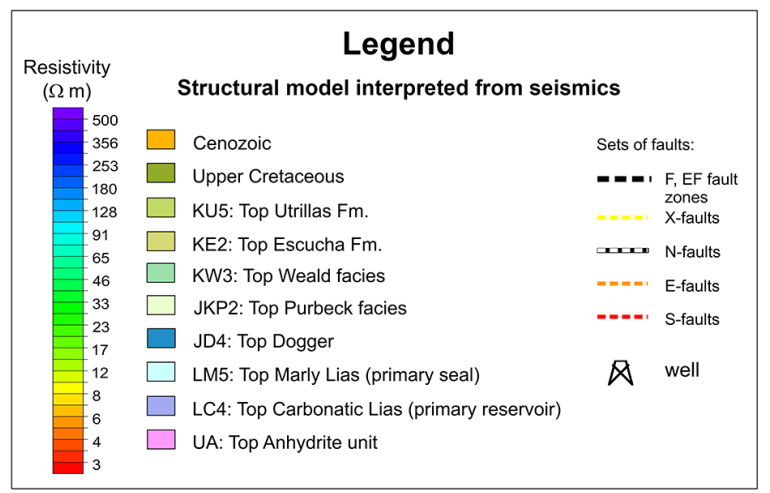

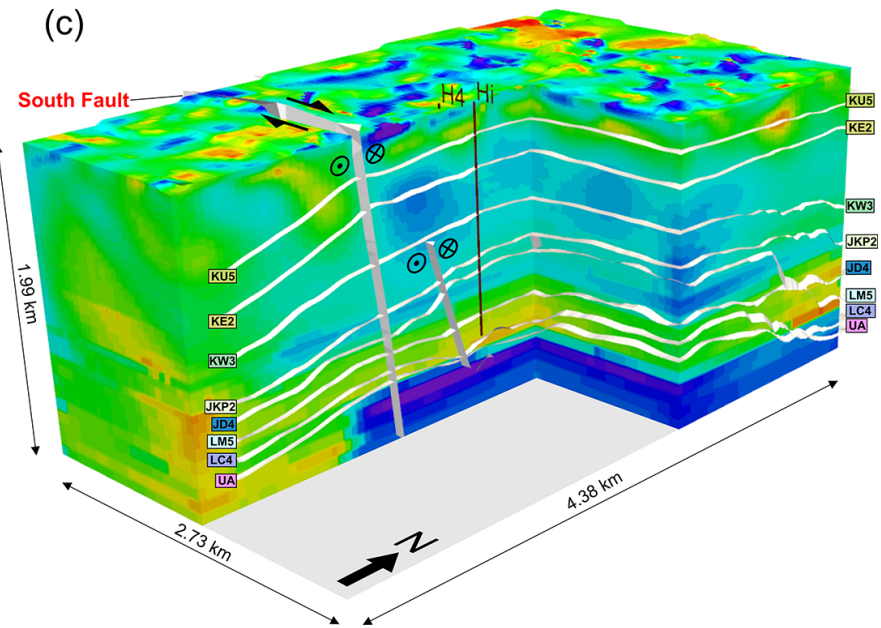

Figure 5. Joint structural interpretation. (a) Profile I of the 3-D MT model and superimposed, $\alpha$ profile of the 3-D seismic model. (b) Section III of the MT model and superimposed, $\beta$ profile of the seismic model. (c) 3-D view of the MT model and the seismic model (structural model). Geoelectrical model: the main resistive layers (R1, C1, R2, and C2) and the F and EF fault regions are indicated. Possible FR2 fracture regions are also specified. The 1-D resistivity models derived in Ogaya et al. (2014) for each well appear superimposed. Seismic model: the top of the main units (black lines) and the main fault sets (X-fault, N-faults, E-faults, and S-faults) are indicated.

depth, and the $\mathrm{H} 4$ data for the deeper structures, from $456 \mathrm{~m}$ depth to the end of the borehole at $1611 \mathrm{~m}$.

The resistivity $(R)$-velocity $(V) \log$ pairs were grouped based on their depth and their relative behaviour (i.e. direct or inverse relationship between resistivity and $P$ wave velocity). In this way, the different depth ranges were determined by empirical observation. The GW1 log data were divided into five groups (S-groups) and the H4 log data into 12 groups (D-groups). Two empirical relationships were calculated for each group: (i) a linear regression of $V$ vs. $\log (R)$ (ER1 hereafter, Table 1, Fig. 6a, c) and (ii) a linear regression of $1 / V$ vs. $1 / R$ (ER2 hereafter, Table 2, Fig. 6b, d).

The empirical relationship ER1 is of the type

$V=a \log R+b$,

where $a$ and $b$ are constants determined by regression analysis for each group (Fig. 6a, c). Table 1 details the value of the constants and the coefficient of determination $R^{2}$ of each group. The groups D8, D9, and D10 are the ones better explained by the linear regression model $\left(R^{2}>0.9\right)$. On the contrary, $R^{2}$ is smaller than 0.05 in $\mathrm{S} 4, \mathrm{~S} 5, \mathrm{D} 1, \mathrm{D} 5, \mathrm{D} 6$, and D11. For those six groups, the constant $a$ is not statistically significant ( $p$ value $>0.02$ )

The empirical relationship ER2 is of the type

$$
\frac{1}{V}=c \frac{1}{R}+d,
$$

where $c$ and $d$ are also constants determined by regression analysis for each group (Fig. 6b, d). Table 2 details the value of the constants and the coefficient of determination $R^{2}$ of each group. In general, the values of the coefficient of determination $R^{2}$ are smaller than for the ER1 relationship. The groups D8, D9, and D10 are again the groups better explained by the linear regression model $\left(R^{2}>0.9\right)$. For the groups S4, S5, D1, D3, D5, and D11 the coefficient of determination $R^{2}$ is smaller than 0.05 . All the constants are sta- 


\section{GW1}

(a)

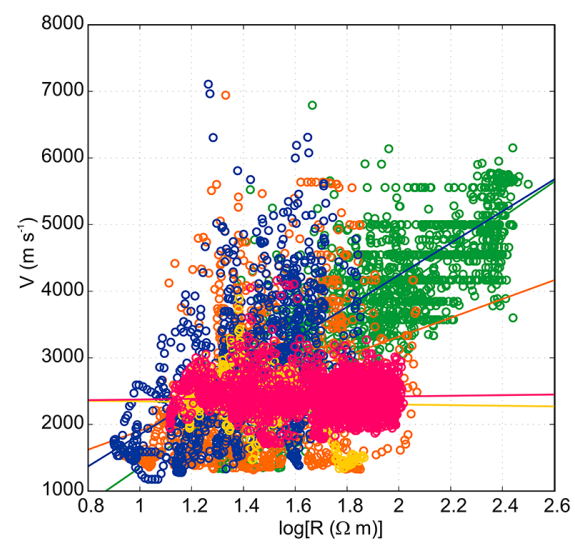

(b)

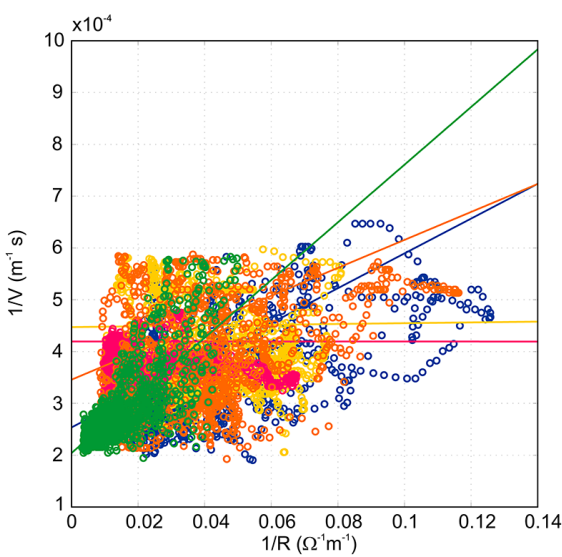

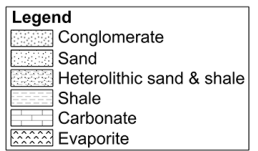

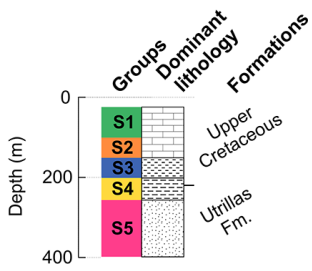

\section{H4}

(c)

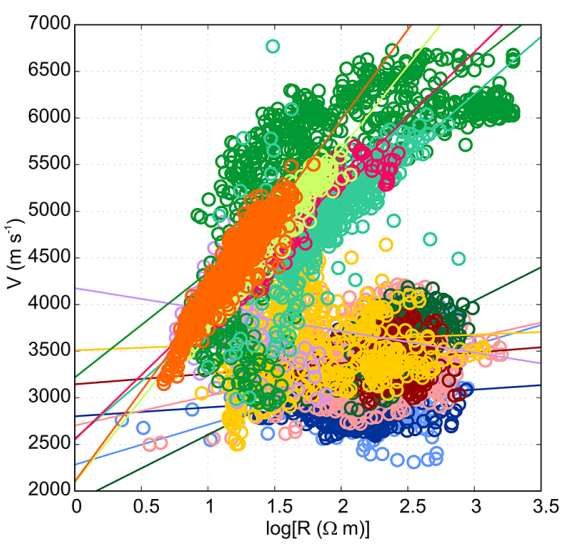

(d)

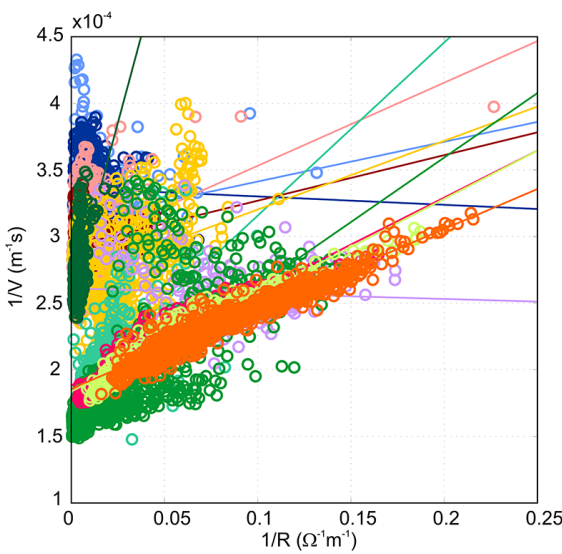

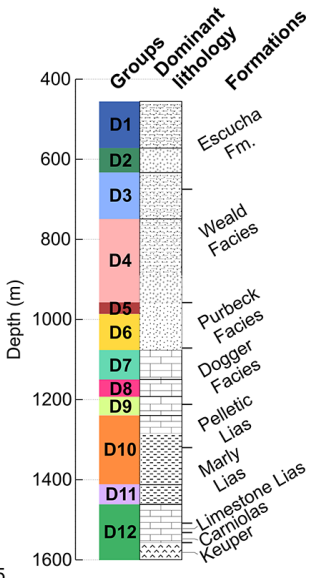

Figure 6. Resistivity vs. Velocity for the GW1 and H4 well logs. The resistivity-velocity log pairs were grouped based on their depth and their relative behaviour: the GW1 log data were divided into five groups (S-groups) and the H4 log data into 12 groups (D-groups). Two empirical relations were calculated for each group: (i) ER1, a linear regression of $V$ vs. $\log (R)$ (a and c) and (ii) ER2, a linear regression of $1 / V$ vs. $1 / R$ (b and d). The figure shows the dominant lithology of all the $\mathrm{S}$ - and D-groups.

tistically significant except the constant $c$ for the groups $\mathrm{S} 4$, S5, D1, D5, and D11 ( $p$ value $>0.02$ ).

The results of the statistical analyses show that the resistivity seems to have limited capacity to predict the velocity in some depth ranges, particularly in groups S4, S5, D1, D5, and D11. This could be partially explained by the small depth variations represented by the different groups and that, in general, the resistivity varies in a wider range of values than the velocity. Note that ER1 and ER2 are local resistivity-velocity relationships established for the Hontomín dataset. However, the ER1 relationship could be associated to the original Faust equation (Faust, 1953) and the ER2 relationship to a recent re-evaluation of the Faust equation for unconsolidated shales (Hacikoylu et al., 2006). The use of both ER1 and ER2 relationships can provide a different estimation of the velocity at the different depths, reproducing the behaviour of both shale and sandstone layers. This can be especially useful to evaluate the accuracy of the approach based on the discrepancies observed between the two relationships. In particular, it could aid in the velocity estimation for those groups in which the resistivity-velocity relationships seem to return the average velocity of the depth range. In general, relationships ER1 and ER2 have a similar behaviour, although they present two important discrepancies: relationship ER1 provides negative velocity values for resistivities below $5 \Omega \mathrm{m}$, and relationship ER2 is less sensitive to variations for resistivity values approximately higher than $900 \Omega \mathrm{m}$. 

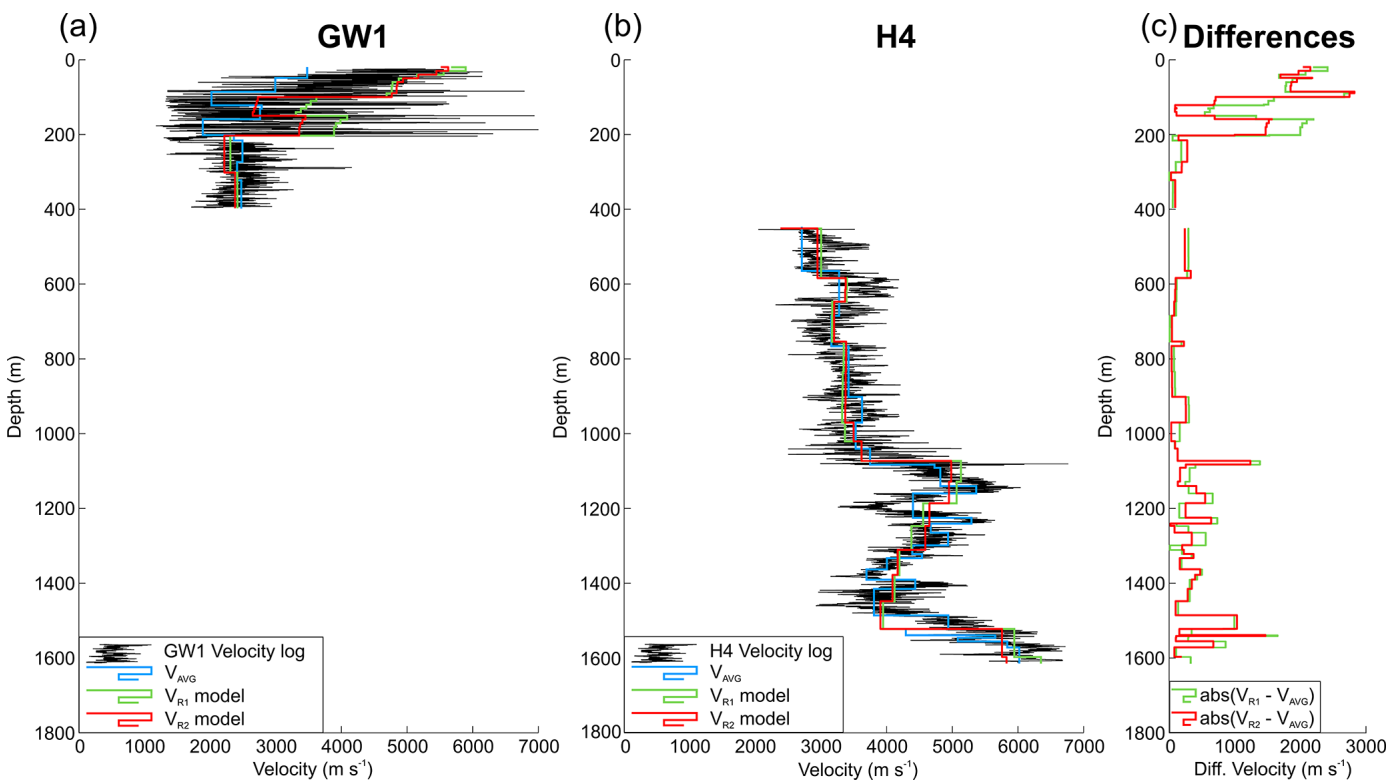

Figure 7. Velocity log data (in black), 1-D velocity models provided by $V_{\mathrm{R} 1}$ (in green), $V_{\mathrm{R} 2}$ (in red), and $V_{\mathrm{AVG}}$ (in blue) for the GW1 (a) and the $\mathrm{H} 4$ (b) wells and differences between the $V_{\mathrm{R}}$ models and $V_{\mathrm{AVG}}(\mathbf{c})$

Table 2. Empirical relationship ER2: linear regression of $1 / V$ vs. $1 / R$.

\begin{tabular}{lrrrr}
\hline Group & Depth $(\mathrm{m})$ & $c(\Omega \mathrm{s})$ & $d\left(\mathrm{~m}^{-1} \mathrm{~s}\right)$ & $R^{2}$ \\
\hline S1 & $0-100$ & $8.70 \times 10^{-3^{*}}$ & $1.62 \times 10^{-4^{*}}$ & 0.6 \\
S2 & $100-150$ & $2.70 \times 10^{-3^{*}}$ & $3.46 \times 10^{-4^{*}}$ & 0.1 \\
S3 & $150-200$ & $3.40 \times 10^{-3^{*}}$ & $2.53 \times 10^{-4^{*}}$ & 0.3 \\
S4 & $200-300$ & $7.53 \times 10^{-5}$ & $4.47 \times 10^{-4^{*}}$ & 0.0002 \\
S5 & $300-400$ & $-8.78 \times 10^{-7}$ & $4.19 \times 10^{-4^{*}}$ & $6.0 \times 10^{-8}$ \\
D1 & $456-573$ & $-6.26 \times 10^{-5}$ & $3.36 \times 10^{-4^{*}}$ & 0.0002 \\
D2 & $573-620$ & $5.20 \times 10^{-3^{*}}$ & $2.55 \times 10^{-4^{*}}$ & 0.3 \\
D3 & $620-750$ & $2.98 \times 10^{-4}$ & $3.11 \times 10^{-4^{*}}$ & 0.03 \\
D4 & $750-958$ & $6.24 \times 10^{-4^{*}}$ & $2.91 \times 10^{-4^{*}}$ & 0.08 \\
D5 & $958-986$ & $3.42 \times 10^{-4}$ & $2.93 \times 10^{-4^{*}}$ & 0.02 \\
D6 & $986-1076$ & $5.16 \times 10^{-4^{*}}$ & $2.69 \times 10^{-4^{*}}$ & 0.09 \\
D7 & $1076-1150$ & $1.30 \times 10^{-3^{*}}$ & $1.86 \times 10^{-4^{*}}$ & 0.5 \\
D8 & $1150-1193$ & $7.05 \times 10^{-4^{*}}$ & $1.88 \times 10^{-4^{*}}$ & 0.91 \\
D9 & $1193-1239$ & $7.23 \times 10^{-4^{*}}$ & $1.84 \times 10^{-4^{*}}$ & 0.93 \\
D10 & $1239-1411$ & $6.00 \times 10^{-4^{*}}$ & $1.86 \times 10^{-4^{*}}$ & 0.93 \\
D11 & $1411-1442$ & $-3.97 \times 10^{-5}$ & $2.61 \times 10^{-4^{*}}$ & 0.003 \\
D12 & $1442-1611$ & $9.68 \times 10^{-4^{*}}$ & $1.66 \times 10^{-4^{*}}$ & 0.6 \\
\hline * $p$ value $<0.02$ & & & &
\end{tabular}

$* p$ value $<0.02$

\subsection{Validation of the relationships}

The 3-D resistivity model (" $R$ " model, hereafter) was converted into two different velocity models using the above mentioned resistivity-velocity relationships: model " $V_{\mathrm{R} 1}$ "

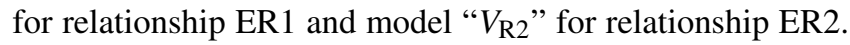
The accuracy of these conversion relationships was assessed by comparing the velocity log data of the GW1 and the $\mathrm{H} 4$ wells (in black in Fig. 7) with the 1-D velocity model pro- vided by $V_{\mathrm{R} 1}$ (in green in Fig.7) and $V_{\mathrm{R} 2}$ (in red in Fig. 7) for each well. These 1-D models are the velocity values of the 3 -D model located at the position of each well. The two models reproduce well the velocity pattern of the sonic-log data in both wells. For the shallow subsurface, relationship ER2 seems to provide an overall slower velocity model than ER1 at the GW1 well location (Fig. 7a). In the deeper part both relationships are very similar at the $\mathrm{H} 4$ well position (Fig. 7b). We observe a quite narrow low-velocity zone at circa $1200 \mathrm{~m}$ depth that is imaged in none of the velocity models, neither $V_{\mathrm{R} 1}$ nor $V_{\mathrm{R} 2}$ (Fig. $7 \mathrm{~b}$ ). This is reasonable, since the $V_{\mathrm{R}}$ models were computed using magnetotellurics and the thickness of this layer $(<50 \mathrm{~m})$ is below the resolution of the method at that depth.

Alcalde et al. (2014) calculated the average petrophysical properties for all the formations using the well-log data of all the existing wells. We used the average velocities (called " $V_{\mathrm{AVG}}$ " hereafter) to compute the equivalent 1 -D velocity models for the GW1 and the H4 wells (in blue in Fig. 7). The differences between the $V_{\mathrm{R}}$ models and $V_{\mathrm{AVG}}$ give an idea of the error of the $V_{R}$ velocity models in the study area (Fig. 7c). For depths shallower than $200 \mathrm{~m}$, the zone where the log data of the GW1 well show significant dispersion related to a high heterogeneous media, the differences between the models are large $\left(>2000 \mathrm{~m} \mathrm{~s}^{-1}\right)$. However, for depths ranging between 200 and $400 \mathrm{~m}$ the log data are characterized by a low variation and the discrepancies between the models are below $300 \mathrm{~m} \mathrm{~s}^{-1}$. For depths deeper than $400 \mathrm{~m}(\mathrm{H} 4)$, there is also a good agreement between the models. The highest discrepancies (above $1000 \mathrm{~m} \mathrm{~s}^{-1}$ ) correspond to layers with a thickness below the resolution of the MT method. 


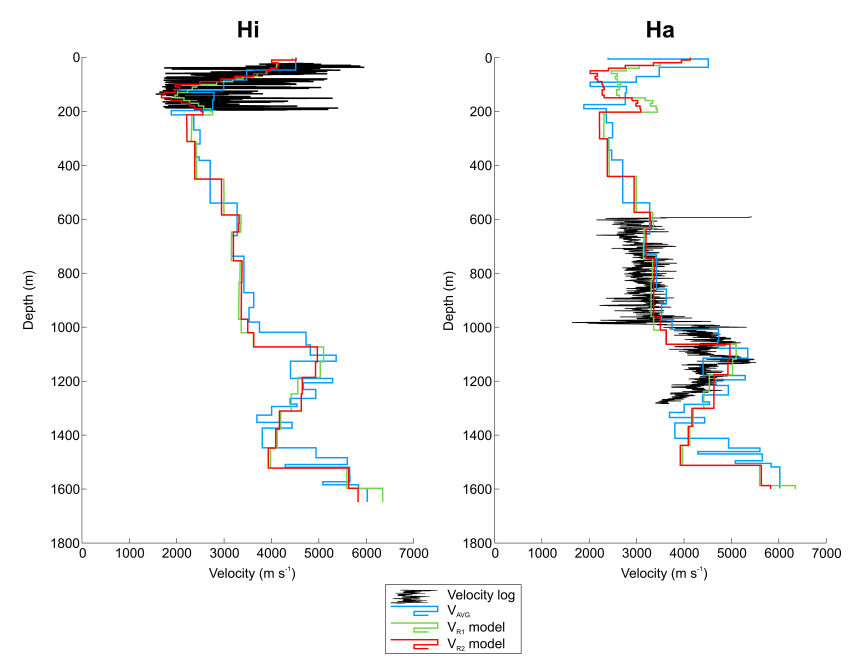

Figure 8. Velocity log data (in black) and 1-D velocity models provided by the $V_{R 1}$ (in green) and $V_{R 2}$ (in red) models for the Hi and the Ha wells together with the predicted sonic logs of these two wells published in Alcalde et al. (2014; $V_{\mathrm{AVG}}$ models, in blue).

We also compared the velocity models provided by the $V_{\mathrm{R} 1}$ and $V_{\mathrm{R} 2}$ models for the $\mathrm{Hi}$ and Ha wells with the predicted sonic logs of these two wells published in Alcalde et al. (2014) $\left(V_{\mathrm{AVG}}\right)$ as well as with the later acquired velocity logs. Figure 8 shows that in general, the differences between the three models are similar to the ones observed for the GW1and $\mathrm{H} 4$ wells. However, the agreement between the models in the shallowest part (first $200 \mathrm{~m}$ ) of the Hi well is considerably better than in the Ha well. For the deeper section, the main differences are located at depths of approximately 500, 1000-1200, and $1500 \mathrm{~m}$.

The available velocity log data ranges from 10 to $200 \mathrm{~m}$ for the Hi well and from 600 to $1284 \mathrm{~m}$ for the Ha well. The first $200 \mathrm{~m}$ of the Hi well-log are well reproduced by all the models (Fig. 8). For depths ranging between 1000 and $1200 \mathrm{~m}$, the predicted $V_{\mathrm{AVG}}$ model reproduces better the velocity behaviour than the $V_{\mathrm{R} 1}$ and $V_{\mathrm{R} 2}$ models. This is reasonable since, as was also seen in Fig. 4, the resistivity model does not image the more resistive layer located at that depth successfully. At $1500 \mathrm{~m}$ depth we do not have velocity log data but one would expect a behaviour similar to the one observed in the $\mathrm{H} 4$ well at that depth. Thus, we associate the differences between the $V_{\mathrm{R}}$ models and the predicted model to the lower resolution of the MT method at those depths.

\section{Shallow subsurface}

\subsection{Static corrections model}

Near surface sediments (e.g. weathering layer, loose sediments or volcanic stockworks) often produce velocity variations that can affect the arrival time of the energy to the recording geophones, especially in onshore data (Taner et al., 1998; Tryggvason et al., 2009). These areas are usually heterogeneously distributed and commonly feature low propagation velocities. This causes unwanted delays in the traces and subsequent disturbances in the coherency of deeper reflections (Juhlin, 1995). Refraction static corrections are standardly used to mitigate this problem (e.g. Malehmir and Bellefleur, 2009). This method uses the differences in travel time of the first breaks to calculate the replacement velocity of a near-surface layer, based on travel time inversion (Lawton, 1989). This velocity model is then used to calculate the time shifts needed to minimize the travel-time difference, usually enhancing considerably the coherence of the reflections.

Refraction statics proved to be the processing step that improved the most the quality of the Hontomín seismic data, in spite of the loss of first arrivals at offsets larger than circa $400 \mathrm{~m}$ (Alcalde et al., 2013b). Due to this "shadow zone", the first arrival picking was performed manually in more than 670000 traces, at offsets ranging from 0 to $500 \mathrm{~m}$. The refraction statics corrections were calculated using a seismic velocity model computed by least squares fitting (Woodward, 1991). The resulting velocity model (Fig. 9) represents a replacement velocity of the first $40 \mathrm{~m}$ of sediments. It provided static corrections of 0 to $40 \mathrm{~ms}$ (RMS of circa $8 \mathrm{~ms}$ ), with residual statics below $4 \mathrm{~ms}$.

The high density of first-break pickings used (over 18000 per $\mathrm{km}^{2}$ ) ensured a robust calculation of the replacement velocity. The statics velocity model (Fig. 9) shows a great amount of detail and a remarkably good correlation with the surface geological map (Fig. 1). The initial model used in the static calculations was a simple half-space model with a constant velocity of $2900 \mathrm{~m} \mathrm{~s}^{-1}$, not containing any a priori geological information. Hence, the good congruence between the outcrop geology and the static corrections model ensures the reliability of the static calculations.

The static corrections model shows a distinct contrast between higher velocities (over $3000 \mathrm{~m} \mathrm{~s}^{-1}$ ) in the central block and areas with lower velocities (below $2750 \mathrm{~m} \mathrm{~s}^{-1}$ ) in the south and east blocks (Fig. 9). This zoning clearly corresponds to the Upper Cretaceous (higher velocity) limestones and the Cenozoic (lower velocity) fluvial sediments, which outcrop in the study area (Fig. 1). These two areas are divided by two high-velocity lineated features, oriented approximately E-W and N-S. These lineations correlate remarkably well with the locations of the East and South faults. The East Fault does not outcrop in the study area and the presence of the South Fault at the surface is unclear. However, their influence in the Hontomín structure is clear, as only $40 \mathrm{~m}$ below the surface they mark the boundary between high- and low-velocity sediments. The smallscale low-velocity areas scattered across the Upper Cretaceous sediments could have their origin in the intense karstification observed in these otherwise high-velocity limestones (Quintà and Tavani, 2012). A high-velocity zone located in 


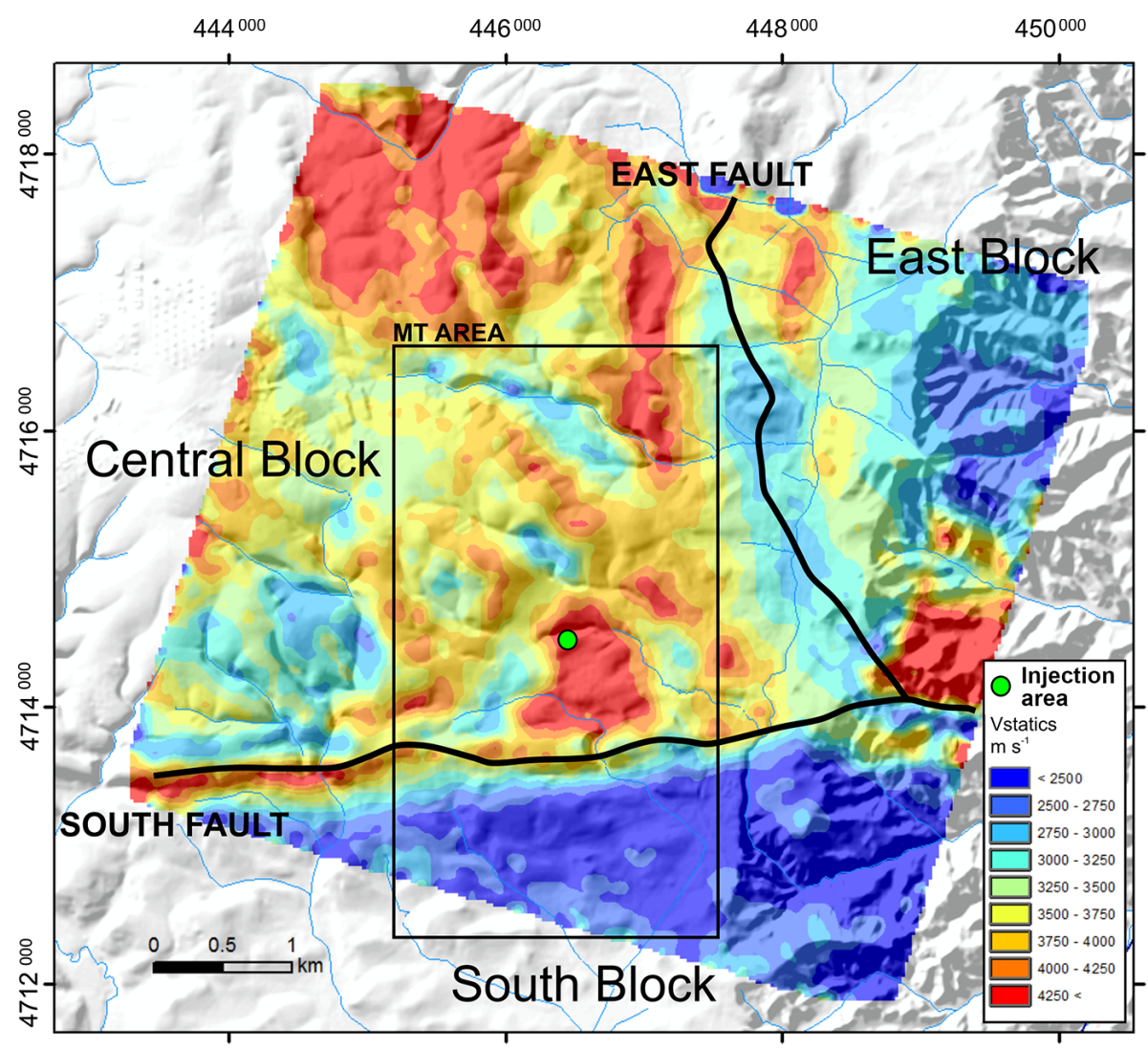

Figure 9. Velocity model used in the static corrections calculations, with the area covered by the MT. The position of the East and South faults, extracted from the seismic data, divides the study area in the central, east, and south blocks. Note that the two faults do not outcrop in the study area.

the eastern margin of the survey area (Fig. 9) corresponds to an area with very low acquisition fold (Alcalde et al., 2013a), and thus has been discarded from the interpretation.

\subsection{Joint interpretation: static corrections model - resistivity-derived models}

The static corrections model displays the replacement velocities for the first $40 \mathrm{~m}$ (Fig. 10a). In order to correlate the structures imaged in this model with the ones displayed in the geoelectrical model (model R), we computed a resistance model (i.e. the inverse of the conductivity-thickness product) for the shallow subsurface (Fig. 10b). This was calculated using the resistivity values provided by the $\mathrm{R}$ model for depths up to $40 \mathrm{~m}$ (following the topography of the model). The resistance model (Fig. 10b) shows values ranging between 0.5 and $6 \Omega \mathrm{m}$ approximately. The BBMT data acquired in the area surrounding the windmills are noisier than the rest (see Fig. 7 in Ogaya et al., 2014) and it is characterized in the model $\mathrm{R}$ by lower resistivity values. The high noise recorded means that the resistivity model $\mathrm{R}$ and all the models generated from it have also lower quality in that region (black dashed line in Fig. 10 indicates the windmill line, centre of the area with low-quality MT data). The resistance model (Fig. 10b) shows certain similarities with the static corrections model (Fig. 10a), in which high-resistance values (in red) can be correlated with high-velocity areas (in red) and vice versa. The resistance model shows a higher nucleation, i.e. a greater amount of scattered bodies than the static corrections model.

In order to evaluate the compatibility of the two methods to image the shallow subsurface, we computed the replacement velocities for the first $40 \mathrm{~m}$ of the velocity models $V_{\mathrm{R} 1}$ (computed using relationship ER1, Fig. 10c) and $V_{\mathrm{R} 2}$ (computed using relationship ER2, Fig. 10d). In both cases, the topography of the area was taken into account. The two models display similar slower (in blue) and faster (in red) regions, but the relationship ER1 (Fig. 10c) provides a smoother result showing a gentler range of velocity variations. On the other hand, relationship ER2 (Fig. 10d) reproduces better the heterogeneities observed in the resistance model (Fig. 10b) and the velocity values seem to be more extreme (in general, higher and lower velocity values). Both models show that the South Fault marks the northern limit of a slower velocity area. 
(a) Statics velocity model

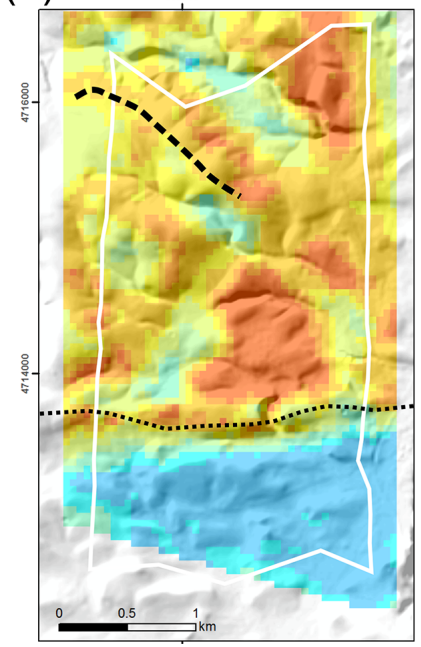

(C) $\mathrm{V}_{\mathrm{R} 1}$ velocity model

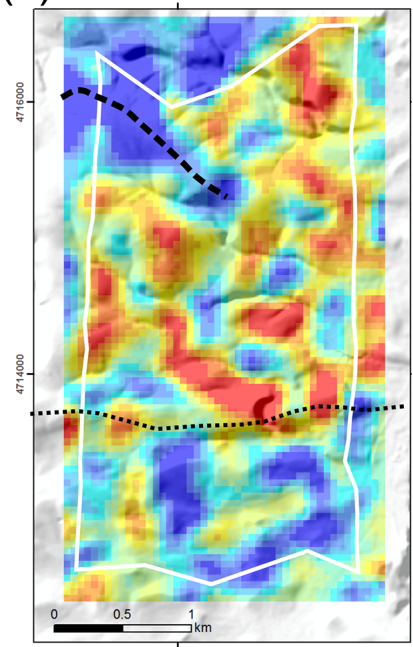

(b) Resistance model

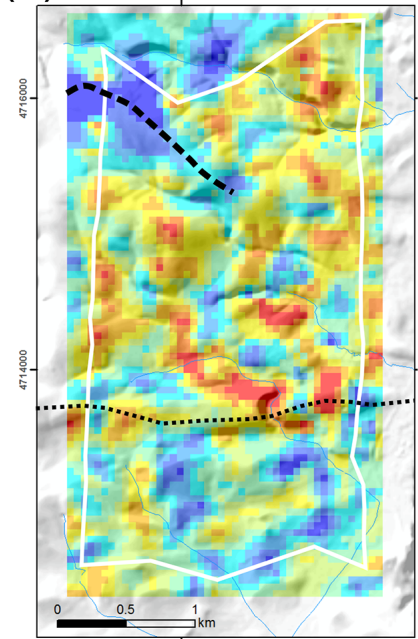

(d)

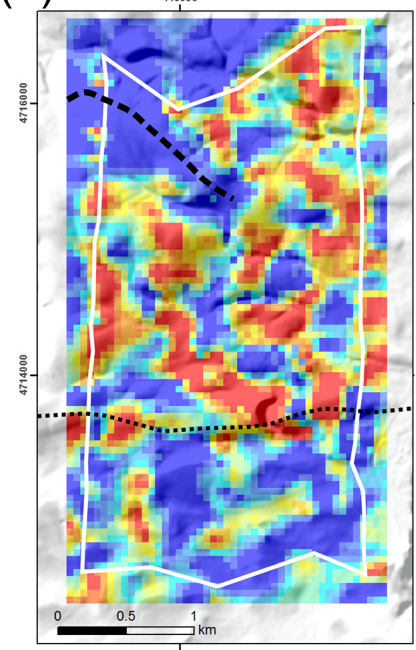

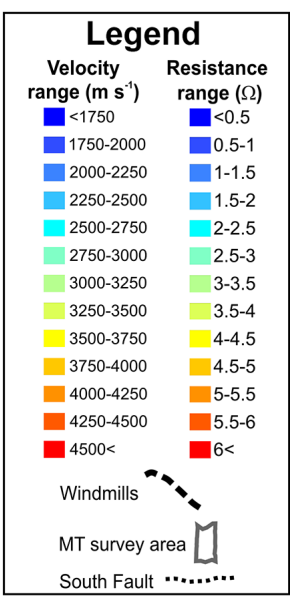

South Fault ..........

Figure 10. Static corrections model from seismic (a), resistance model for the first $40 \mathrm{~m}$ (b) and replacement velocity model for the first $40 \mathrm{~m}$ computed using $V_{\mathrm{R} 1}$ (c) and $V_{\mathrm{R} 2}$ (d). Black dashed lines indicate the windmill line and the centre of the area with low-quality data.

Since the two velocity models display the same velocity structure and the bodies are better defined in the model derived using relationship ER1, we used the $V_{\mathrm{R} 1}$ model (Fig. 10c) in the comparison with the static corrections model (Fig. 10a). In general, the two models ( $V_{\mathrm{R} 1}$ model and static corrections model) reveal similar velocity patterns, with the South Fault marking the limit between higher velocities to the north and lower velocities to the south. The area surrounding the windmills shows a remarkably velocity variation between the models. This area corresponds to the noisiest area in the resistivity model $\mathrm{R}$, and hence, this area is discarded for a further interpretation. The south block (located to the south of the South Fault) is characterized by slow velocities in both models, but has more structures in $V_{\mathrm{R} 1}$. In general, there is an agreement between the areas with high discrepancies between the two models and the quaternary unconsolidated sediments (see geological map in Fig. 1). The sediments of the south block are mainly composed by Quaternary sandstones (gravel and clay) and Cenozoic sandstones (sandstones and clay - Fig. 1). Thus the differences observed in this area could be due to variations of clay or water content. The accumulation of gravel and sandstones in the south block could imply different levels of water content which could result in important resistivity variations. Finally, the high-velocity area displayed to the north of the South Fault show the highest velocity values in the two models, but has more lateral continuity in the static corrections model. The most significant difference is observed in the southwestern part of that high-velocity area: it corresponds to a homogeneous area in the static corrections model whereas has a ring shape with a low-velocity area in the middle, in the model derived from the resistivity model (SW part of the cen- 
tral block in Fig. 10c). The presence of unconsolidated sediments could also be responsible for the low-velocity areas observed in the centre of this ring. The minor discrepancies between the two models observed in the central block could be originated by the existence of karstic structures.

\section{Discussion}

The joint interpretation of the seismic and magnetotelluric data acquired at the Hontomín site is analysed from a structural and a petrophysical point of view. Firstly, it is difficult to establish a direct structural link between the two datasets because of the nature of the two methods (i.e. the resistivity model does not image lithologies but geoelectrical properties). However, the depth and geometry of the main resistive layers agree with the structure defined by the different surfaces in the centre of the study area (i.e. the area covered by the boreholes). Outside the injection area, the presence of the South and the East faults alter the geoelectrical behaviour of the different layers and produces the major differences observed between the models. The correlation of the two models provides a 2-fold characterization of the existing faults, contributing to a greater structural constrain and allowing to estimate the important hydrogeological properties. For instance, the South Fault seems not to have an important displacement in the structural model but could be associated to an important fluid circulation according to the resistivity model, especially in the eastern part. In the same way, some minor resistivity changes imaged in the Dogger and Purbeck facies could suggest a small fluid circulation along small fractures that are not observed in the seismic data, potentially due to very small or inexistent vertical displacement. Understanding these hydrogeological properties is essential for ensuring the safety of the $\mathrm{CO}_{2}$ site and to forecast the behaviour of the injected $\mathrm{CO}_{2}$ in the case of unforeseen leakage events.

In reference to the resistivity-velocity relationships, we derived two different empirical relationships to convert the resistivity model to a velocity model: (i) a linear regression of $V$ vs. $\log (R)(\mathrm{ER} 1)$ and (ii) a linear regression of $1 / V$ vs. $1 / R$ (ER2). Based on the obtained results, the use of more than one empirical relationship is advisable because the discrepancies between the different velocity models indicate areas with higher and lower agreement, helping to constrain the error and the accuracy of the approaches. This is especially useful for those depth ranges where velocity is independent of resistivity and the derived relationships are only able to provide an average velocity value. A linear regression of $V$ vs. $\log (R)$ (relationship ER1) seemed to reproduce slightly better than a linear regression of $1 / V$ vs. $1 / R$ (relationship ER2) the trend of the log data (Fig. 6). The derived velocity models $\left(V_{\mathrm{R} 1}\right.$ and $\left.V_{\mathrm{R} 2}\right)$ are very similar but for the near-surface ER1 provides a smoother velocity model. The relationships used were empirically derived from velocity- resistivity cross-plots without providing a full insight in their physical basis. Thus, future work should include exploring how these relationships accommodate parameters such as effect of porosity, water saturation, salinity or clay content, in order to refine the resistivity-velocity relationships. Besides we would need to also consider other petrophysical properties for a further petrological interpretation of the derived Sand D-groups since the relationship between them and their dominant lithologies is not obvious.

Despite the lack of petrological constrains, the computed local empirical velocity-resistivity relationships allowed us to derive a velocity model from the resistivity (MT) model using the available log data. Although the level of resolution of the MT method is different from the other two techniques (i.e. well-log data and seismics), it has proven its capability to provide satisfactory velocity models of the site. The quality of the derived velocity models is expected to be higher in the centre of the study area (i.e. in the surroundings of the wells) than in those areas where the presence of the South and the East faults strongly alter the geoelectrical behaviour of the different layers.

In the shallow subsurface, the comparison between the static corrections model and the derived velocity models for the first $40 \mathrm{~m}$ showed relatively small discrepancies between the two models. These discrepancies are reasonable since, apart from the error inherent to the approach, one model was computed from seismic (i.e. sensitive to velocity/density changes) and the other was computed from magnetotelluric (i.e. sensitive to electrical conductivity) data. Hence, the correlation of the two methods gives a more complete information of the shallow sediments, suggesting possible variations in clay and water content. On the other hand, the joint interpretation of the two models provides little information about the extent and geometry of the existing karstic areas. The 3D seismic and 3-D MT surveys were designed for imaging deeper structures, including the target reservoir and seal formations which are located at circa $1.5 \mathrm{~km}$ depth. Thus, capturing the inherent complexity of the shallow subsurface and in particular, of the karst (i.e. variable size, composition of the filling of the voids, seasonal variation of the water table, potential cementation) could be out of the limits of resolution of the methods and methodology applied in this work. An interesting task to face in the future would be to merge these results with other geophysical (e.g. Benjumea et al., 2016) and geochemical (Elio et al., 2013; Nisi et al., 2013) studies carried out in the area, to better constrain the location and geometry of the karst, and clay and water content variations.

The joint interpretation presented here contributes to the better understanding of the Hontomín site subsurface. Both the predicted model presented in Alcalde et al. (2014) and the resistivity model presented in Ogaya et al. (2014) anticipated the structure and the physical properties of the recently drilled $\mathrm{Hi}$ and $\mathrm{Ha}$ wells accurately. Facing the future, the work presented here constitutes a valuable starting point for a joint inversion of the seismic and magnetotelluric datasets. 
This could provide a more constrained understanding of the fluid circulation along the faults, which have important implications for the safety of the $\mathrm{CO}_{2}$ storage pilot site and the detectability of diffuse $\mathrm{CO}_{2}$ leakages.

\section{Conclusions}

The joint interpretation of the structural, velocity, and resistivity model contributes to a more robust understanding of the subsurface, better characterizing the existing faults - a key aspect for the risk assessment of the Hontomín pilot storage site. The combined interpretation of the geoelectrical and the structural model derived from the seismic data allowed estimating the fluid flow characteristics of the major faults in the area. The methodology used to derive velocity from resistivity has been successfully applied at the Hontomín site, pointing out the importance of employing more than one empirical relationship between the properties to have a better control of the uncertainties inherent to the approach. The major differences observed between the velocity models derived from the resistivity model and the predicted and logged velocity in the injection and monitoring wells are attributed to the lower resolution of the magnetotelluric method. The joint interpretation for depths shallower than $40 \mathrm{~m}$ allowed extracting information about the characteristics of the shallow sediments, suggesting variations in clay and water content. The seismic and magnetotelluric methods have shown their compatibility across scales, pointing out the importance of joint interpretation in characterization surveys. This work provides a more complete picture of the Hontomín site subsurface, essential in the monitoring of the site, and establishes the basis for a potential joint inversion of the two geophysical datasets.

Acknowledgements. This work is dedicated to the memory of Andrés Pérez-Estaún, brilliant scientist, colleague, and friend. The authors sincerely thank Ian Ferguson and an anonymous reviewer for their useful comments on the manuscript. Xènia Ogaya is currently supported in the Dublin Institute for Advanced Studies by a Science Foundation Ireland grant IRECCSEM (SFI grant 12/IP/1313). Juan Alcalde is funded by NERC grant NE/M007251/1, on interpretational uncertainty. Juanjo Ledo, Pilar Queralt and Alex Marcuello thank Ministerio de Economía y Competitividad and EU Feder Funds through grant CGL201454118-C2-1-R. Funding for this Project has been partially provided by the Spanish Ministry of Industry, Tourism and Trade, through the CIUDEN-CSIC-Inst. Jaume Almera agreement (ALM-09-027: Characterization, Development and Validation of Seismic Techniques applied to $\mathrm{CO}_{2}$ Geological Storage Sites), the CIUDEN-Fundació Bosch i Gimpera agreement (ALM-09-009 Development and Adaptation of Electromagnetic techniques: Characterisation of Storage Sites) and the project PIERCO2 (Progress In Electromagnetic Research for $\mathrm{CO}_{2}$ geological reservoirs CGL2009-07604). The CIUDEN project is co-financed by the European Union through the Technological Development Plant of
Compostilla OXYCFB300 Project (European Energy Programme for Recovery).

Edited by: J. Alvarez-Marron

\section{References}

Alcalde, J., Martí, D., Calahorrano, A., Marzán, I., Ayarza, P., Carbonell, R., Juhlin, C., and Pérez-Estaún, A.: Active seismic characterization experiments of the Hontomín research facility for geological storage of $\mathrm{CO}_{2}$, Spain, Int. J. Greenh. Gas Con., 19, 785-795, 2013a.

Alcalde, J., Martí, D., Juhlin, C., Malehmir, A., Sopher, D., Saura, E., Marzán, I., Ayarza, P., Calahorrano, A., Pérez-Estaún, A., and Carbonell, R.: 3-D reflection seismic imaging of the Hontomín structure in the Basque-Cantabrian Basin (Spain), Solid Earth, 4, 481-496, doi:10.5194/se-4-481-2013, 2013b.

Alcalde, J., Marzán, I., Saura, E., Martí, D., Ayarza, P., Juhlin, C., Pérez-Estaún, A., and Carbonell, R.: 3-D geological characterization of the Hontomín $\mathrm{CO}_{2}$ storage site, Spain: Multidisciplinary approach from seismic, well-log and regional data, Tectonophysics, 627, 6-25, doi:10.1016/j.tecto.2014.04.025, 2014.

Bedrosian, P. A.: MT+, Integrating Magnetotellurics to determine Earth Structure, Physical State and, Processes, Surv. Geophys., 28, 121-167, doi:10.1007/s10712-007-9019-6, 2007.

Benjumea, B., Macau, A., Gabàs, A., and Figueras, S.: Characterization of a complex near-surface structure using well logging and passive seismic measurements, Solid Earth, 7, 685-701, doi:10.5194/se-7-685-2016, 2016.

Brito dos Santos, W. L., Ulrych, T. J., and De Lima, O. A. L.: A new approach for deriving pseudovelocity logs from resistivity logs, Geophys. Prospect., 36, 83-91, 1988.

Canal, J., Delgado, J., Falcón, I., Yang, Q., Juncosa, R., and Barrientos, V.: Injection of $\mathrm{CO}_{2}$-saturated water through a siliceous sandstone plug from the Hontomín test site (Spain): Experiment and modelling, Environ. Sci. Technol., 47, 159-167, 2013.

Chadwick, A., Arts, R., Bernstone, C., May F., Thibeau, S., and Zweigel, P.: Best practice for the storage of $\mathrm{CO}_{2}$ in saline aquifers, British Geological occasional Publication, 14, 2008.

Chadwick, R., Zweigel, P., Gregersen, U., Kirby, G. Holloway, S., and Johannessen, P.: Geological reservoir characterization of a $\mathrm{CO}_{2}$ storage site: The Utsira Sand, Sleipner, northern North Sea, Energy, 29, 1371-1381, 2004.

Eberhart-Phillips, D., Stanley, W. D., Rodriguez, B. D., and Lutter, W. J.: Surface seismic and electrical methods to detect fluids related to faulting, J. Geophys. Res., 100, 12919-12936, doi:10.1029/94JB03256, 1995.

Eid, R., Ziolkowski, A., Naylor, M., and Pickup, G.: Seismic monitoring of $\mathrm{CO}_{2}$ plume growth, evolution and migration in a heterogeneous reservoir: Role, impact and importance of patchy saturation, Int. J. Greenh. Gas Con., 43, 70-81, 2015.

Elío, J., Nisi, B., Ortega, M. F., Mazadiego, L. F., Vaselli, O., and Grandia, F.: $\mathrm{CO}_{2}$ soil flux baseline at the Technological Development Plant for $\mathrm{CO}_{2}$ Injection at Hontomín (Burgos, Spain), Int. J. Greenh. Gas Con., 18, 224-236, 2013.

European Union (EU): Directive 2009/31/EC of the European Parliament and of the council of 23 April 2009 on the geolog- 
ical storage of carbon dioxide and amending Council Directive 85/337/EEC, European Parliament and Council Directives 2000/60/EC, 2001/80/EC, 2004/35/EC, 2006/12/EC, 2008/1/EC and Regulation (EC) No 1013/2006, 2009.

Faust, L. Y.: A velocity function including lithologic variation, Geophysics, 18, 271-288, 1953.

Förster, A., Norden, B., Zinck-Jørgensen, K., Frykman, P., Kulenkampss, J., Spangerberg, E., Erzinger, J., Zimmer, M., Kopp, J., Borm, G., Julin, C., Cosma, C., and Hurter, S.: Baseline characterization of the $\mathrm{CO}_{2}$ SINK geological storage site at Ketzin, Germany, Environ. Geosci., 13, 145-161, 2006.

Gallardo, L. A. and Meju, M. A.: Characterization of heterogeneous near-surface materials by joint 2-D inversion of DC resistivity and seismic data, Geophys. Res. Lett., 30, 1658, doi:10.1029/2003GL017370, 2003.

Hacikoylu, P., Dvorkin, J., and Mavko, G.: Resistivity-velocity transforms revisited, The Leading Edge, 25, 1006-1009, doi:10.1190/1.2335159, 2006.

Harris, P. and MacGregor, L.: Determination of reservoir properties from the integration of CSEM and seismic data, First Break, 24, 15-21, 2006.

Hart, B. S.: Definition of subsurface stratigraphy, structure and rock properties from 3-D seismic data, Earth-Sci. Rev., 47, 189-218, 1999.

Hesthammer, J., Landrø, M., and Fossen, H.: Use and abuse of seismic data in reservoir characterisation, Mar. Petrol. Geol., 18, 635-655, 2001.

IPCC-Intergovernmental Panel on Climate Change: IPCC Special Report on Carbon Dioxide Capture and Storage, Prepared by Working Group III of the Intergovernmental Panel on Climate Change, edited by: Metz, B., Davidson, O., de Coninck, H. C., Loos, M., and Meyer, L. A., Cambridge University Press, Cambridge, United Kingdom and New York, NY, USA, 2005.

Juanatey, M., Tryggvason, A., Juhlin, C., Bergström, U., Hübert, J., and Pedersen, L. B.: MT and reflection seismics in northwestern Skellefte Ore District, Sweden, Geophysics, 78, B65-B76, doi:10.1190/geo2012-0169.1, 2013.

Juhlin, C.: Imaging of fracture zones in the Finnsjon area, central Sweden, using the seismic reflection method, Geophysics, 60, 66-75, 1995.

Lawton, D. C.: Computation of refraction static corrections using first-break traveltime differences, Geophysics, 54, 1289-1296, 1989.

MacGregor, L.: Integrating seismic, CSEM, and well log data for reservoir characterization, The Leading Edge, 31, 268-277, 2012.

Malehmir, A. and Bellefleur, G.: 3-D seismic reflection imaging of volcanic-hosted massive sulfide deposits: Insights from reprocessing Halfmile Lake data, New Brunswick, Canada, Geophysics, 74, B209-B219, doi:10.1190/1.3230495, 2009.

Moorkamp, M., Heincke, B., Jegen, M., Roberts, A. W., and Hobbs, R. W.: A framework for 3-D joint inversion of MT, gravity and seismic refraction data, Geophys. J. Int., 184, 477-493, doi:10.1111/j.1365-246X.2010.04856.x, 2011.

Martínez-Landa, L., Rötting, T. S., Carrera, J., Russian, A., Dentz, M., and Cubillo, B.: Use of hydraulic tests to identify the residual $\mathrm{CO}_{2}$ saturation at a geological storage site, Int. J. Greenh. Gas Con., 19, 652-664, 2013.
Muñoz, G., Ritter, O., and Moeck, I.: A target-oriented magnetotelluric inversion approach for characterizing the low enthalpy Gross Schoenebeck geothermal reservoir, Geophys. J. Int., 183, 1199-1215, 2010.

Nakatsuka, Y., Xue, Z., Garcia, H., and Matsuoka, T.: Experimental study on $\mathrm{CO}_{2}$ monitoring and quantification of stored $\mathrm{CO}_{2}$ in saline formations using resistivity measurements, Int. J. Greenh. Gas Con., 4, 209-216, doi:10.1016/j.ijggc.2010.01.001, 2010.

Nisi, B., Vaselli, O., Tassi, F., Elío, J., Delgado Huertas, A., Mazadiego, L. P., and Ortega, M. F.: Hydrogeochemistry of surface and spring waters in the surroundings of the $\mathrm{CO}_{2}$ injection site at Hontomín-Huermeces (Burgos, Spain), Int. J. Greenh. Gas Con., 14, 151-168, 2013.

Ogaya, X., Ledo, J., Queralt, P., Marcuello, Á., and Quintà, A.: First geoelectrical image of the subsurface of the Hontomín site (Spain) for $\mathrm{CO}_{2}$ geological storage: A magnetotelluric 2-D characterization, Int. J. Greenh. Gas Con., 13, 168-179, 2013.

Ogaya, X., Queralt, P., Ledo, J., Marcuello, A., and Jones, A.G.: Geoelectrical baseline model of the subsurface of the Hontomín site (Spain) for $\mathrm{CO}_{2}$ geological storage in a deep saline aquifer: a 3-D Magnetotelluric characterisation, Int. J. Greenh. Gas Con., 27, 120-138, 2014.

Permanyer, A., Márquez, G., and Gallego, J. R. R.: Compositional variability in oils and formation waters from the Ayoluengo and Hontomín fields (Burgos, Spain), Implications for assessing biodegradation and reservoir compartmentalization, Org. Geochem., 54, 125-139, 2013.

Quintà, A. and Tavani, S.: The foreland deformation in the southwestern Basque-Cantabrian Belt (Spain), Tectonophysics, 576577, 4-19, doi:10.1016/j.tecto.2012.02.015, 2012.

Rubio, F. M., Ayala, C., Gumiel, J. C., and Rey, C.: Caracterización mediante campo potencial y teledetección de la estructura geológica seleccionada para planta de desarrollo tecnológico de almacenamiento geológico de $\mathrm{CO}_{2}$ en Hontomín (Burgos), IGMEInstituto Geológico y Minero de España Technical Report, 182 pp., 2011.

Solon, F. F., Fontes, S. L., and Meju, M. A.: Magnetotelluric imaging integrated with seismic, gravity, magnetic and well-log data for basement and carbonate reservoir mapping in the São Francisco Basin, Brazil, Petrol. Geosci., 21, 285-299, 2015.

Taner, M. T., Wagner, D. E., Baysal, E., and Lu, L.: A unified method for 2-D and 3-D refraction statics, Geophysics, 63, 260274, 1998

Tryggvason, A., Schmelzbach, C., and Juhlin, C.: Traveltime tomographic inversion with simultaneous static corrections - Well worth the effort, Geophysics, 74, WCB25-WCB33, 2009.

Ugalde, A., Villaseñor, A., Gaite, B., Casquero, S., Martí, D., Calahorrano, Marzán, I., Carbonell, R., and Estaun, A. P.: Passive Seismic Monitoring of an Experimental $\mathrm{CO}_{2}$ Geological Storage Site in Hontomín (Northern Spain), Seismol. Res. Lett., 84, 75-84, 2013.

Vilamajó, E., Queralt, P., Ledo, J., and Marcuello, A.: Feasibility of Monitoring the Hontomín (Burgos, Spain) $\mathrm{CO}_{2}$ Storage Site Using a Deep EM Source, Surv. Geophys., 34, 441-461, 2013.

Vilamajó, E., Rondeleux, B., Queralt, P., Marcuello, A., and Ledo, J.: A land controlled-source electromagnetic experiment using a deep vertical electric dipole: experimental settings, processing, and first data interpretation, Geophys. Prospect., 63, 1527-1540, 2015. 
Werthmüller, D., Ziolkowski, A., and Wright, D.: Background resistivity model from seismic velocities, Geophysics, 78, E213E223, doi:10.1190/GEO2012-0445.1, 2013.

White, D.: Seismic characterization and time-lapse imaging during seven years of $\mathrm{CO}_{2}$ flood in the Weyburn field, Saskatchewan, Canada, Int. J. Greenh. Gas Con., 16, S78-S94, doi:10.1016/j.ijggc.2013.02.006, 2013.
Woodward, D. J.: Inversion of Seismic Refraction Data, Geophysics Division Technical Report No. 114, available at: http://www.gns. cri.nz/ (last access: 29 November 2015), 1991. 